\title{
The use of GIS tools for road infrastructure safety management
}

\author{
Marcin Budzyński ${ }^{1,}$, , Wojciech Kustra ${ }^{1}$, Romanika Okraszewska $^{1}$, Kazimierz Jamroz ${ }^{1}$, and Jerzy Pyrchla ${ }^{2}$ \\ ${ }^{1}$ Gdansk University of Technology, Faculty of Civil and Environmental Engineering, Department of Highway Engineering, \\ Narutowicza St. 11/12, 80-233 Gdansk, Poland \\ ${ }^{2}$ Gdansk University of Technology, Faculty of Civil and Environmental Engineering, Department of Geodesy, Narutowicza St. 11/12, \\ 80-233 Gdansk, Poland
}

\begin{abstract}
There are many factors that influence accidents and their severity. They can be grouped within the system of man, vehicle and environment. The article focuses on how GIS tools can be used to manage road infrastructure safety. To ensure a better understanding and identification of road factors, GIS tools help with the acquisition of road parameter data. Their other role is helping with a clear and effective presentation of risk ranking. GIS is key to identifying high-risk sections and supports the effective communication of safety levels. This makes it a vital element of safety management. The article describes the use of GIS for the collection and visualisation of road parameter data which are not available in any of the existing databases, i.e. horizontal curve parameters. As we know from research and statistics, they are important factors that determine the safety of road infrastructure. Finally, new research is proposed as well as the possibilities for applying GIS tools for the purposes of road safety inspection.
\end{abstract}

\section{Introduction}

In the last decade nearly 65,000 people were killed and more than 700,000 were injured in Poland's road accidents. Each year more than 70,000 road users fall victim to road traffic. World Bank experts estimate that each year Poland loses $2.7 \%$ of its GDP due to road accidents. Despite a clear reduction in fatalities in recent years, about 3,000 people are killed in accidents on the entire road network. With a demographic rate (number of fatalities per population) of 10, Poland is the EU's worst performing country. There are many factors that influence accidents and their severity. They can be grouped within the system of man, vehicle and environment. The article focuses on how GIS tools can be used to collect, analyse and visualise roadside factors which may lead to accidents. To ensure a better understanding and identification of road factors, GIS tools help with the acquisition of road parameter data. Their other role is helping with a clear and effective presentation and communication of risk and risk ranking.

\section{GIS in road transport}

In the early 1960s GIS technology was used to create digital cartographic resources offering a spatial presentation of specific features. As the system evolved, GIS was able to present the dynamics of phenomena in terms of time and space [1]. It is based on the concept of overlaying different mapped features on top of each other to determine patterns and causes of spatial phenomena [2]. A geographic information system (GIS) by linking attribute data to spatial data can now be put to use in a number of fields, including transport.

Many countries utilize Geographic Information Systems (GIS) to manage existing transport resources and enhance the effectiveness and efficiency of transport operations. Most researchers found that GIS brings efficiency in data handling and effectiveness in data analysis. The development of GIS applications to road accident analysis has also become a trend [3]. GIS enables a new method in organizing geographical data through its database management system that facilitates the storage, organization and retrieval of digital records [4]. The literature includes a number of examples of how GIS can be used in road safety management [5][6][7][8].

As regards road transport, GIS applications range from simple maps presenting a specific feature (number of cars, accidents, road density, etc.) in terms of space to maps presenting the time and space dynamics of how certain phenomena change. The tool is commonly used for visualising transport data which are collected for official databases such as Central Statistical Office databases (fleet size, fuel prices, etc.) or SEWIK (Accident and Collision Reporting System, number of accidents to identify black spots or black zones) [7]. GIS can be used for accident analysis to examine spatial characteristics of accident locations. Point-in-polygon overlays link the characteristics of the surroundings to the characteristics of the accident. GIS is used as a tool for studying the relation between factors or the effect of factors and events and processes such as the relationship between average speed, speed variation, and accident rates [6] where GIS tools are used to achieve the appropriate data and derive the weight matrix among

\footnotetext{
* Corresponding author: marcin.budzynski@pg.edu.pl
} 
neighbouring segments which is necessary for the spatial model. More complex analyses, e.g. the effects of characteristic factor features (roadside, type of road surface, road geometric parameters, etc.) on the occurrence of an incident are made possible by point-online overlays in which attributes of the road infrastructure can be added. Analyses such as these are an important part of risk management (Fig. 1). The role of risk assessment is to improve road transport safety and define the priorities for public health and public and individual safety [9].

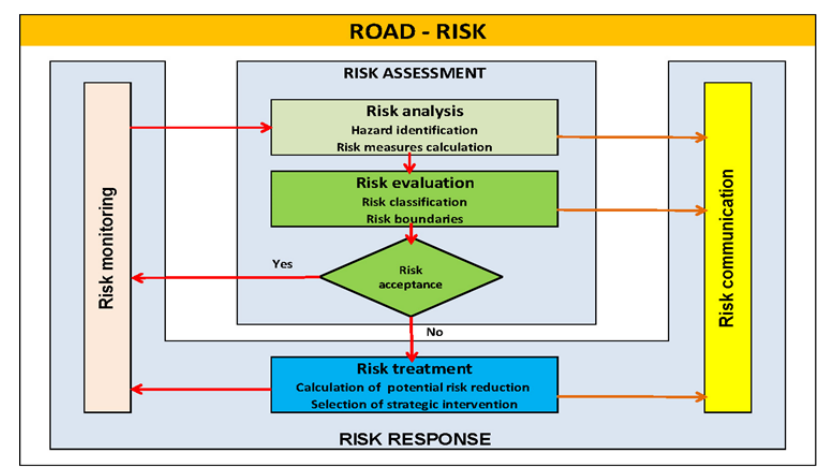

Fig. 1. Diagram of road risk management [11].

In Poland GIS tools are used for safety management at two levels. The first level is designed to identify the exact location of accidents (the Police have only been using GPS for this purpose for three years) and present the effects of road accident database exploration by visualising them on dedicated maps (of countries, regions, counties) of road sections. The result is a clear depiction of different types of risk rankings by area, road network or section.

The second level is designed to collect and visualise road parameter data which are not normally covered in any of the available databases. Tools are needed to ensure that road factor data can be sourced effectively for inclusion in road safety models. These include GIS tools because they can acquire data from the road network automatically, especially as regards geometric parameters.

\section{Road infrastructure management (RISM)}

The objective of road safety infrastructure management (RISM) is to ensure that when road infrastructure is planned, designed, built and used road risks can be systematically identified, assessed for their consequences and eliminated or mitigated. The consequences are measured with the number of accidents, injuries, fatalities and road accident costs. To build RISM tools, we can build on the requirements set out in Directive 2008/96/EC [10]. It covers both planned and existing road networks. Poland introduced these requirements a few years ago.

Because GIS is vital to identifying high-risk sections and effectively communicating safety levels, it plays a key part in the process of safety management.

\section{Examples of gis applications}

Poland's first application of risk management as part of highway engineering goes back to 2006, when it joined a collaboration with EuroRAP (European Road Assessment Programme). Next, in 2008 as work on the Road Safety Programme for National Roads until 2013, "National Roads GAMBIT" progressed, a suggestion was made to base national roads safety management on risk management methods [12]. Risk maps attracted increasing interest from the media, politicians and road users and were made available on Polish and EuroRAP websites. The maps are still in use today. They inform motorists about the risk on the road network (national and local roads). This helps them choose the lowest risk road and be extra careful when using high-risk sections. In addition, the maps help road authorities with making informed decisions about possible safety treatments. The maps also highlight the differences in safety levels across Poland's national roads and in other countries.

Poland did not do well in such comparisons. Because the results were published at the European forum, road authorities and traffic managers were forced to take more effective action to reduce risk on national roads. Fig. 2 shows a comparison of individual risk maps (measured as concentration of serious accidents) for national roads. The progress of recent years is clear with fewer very high-risk (black sections) and high-risk sections on national roads (red sections).

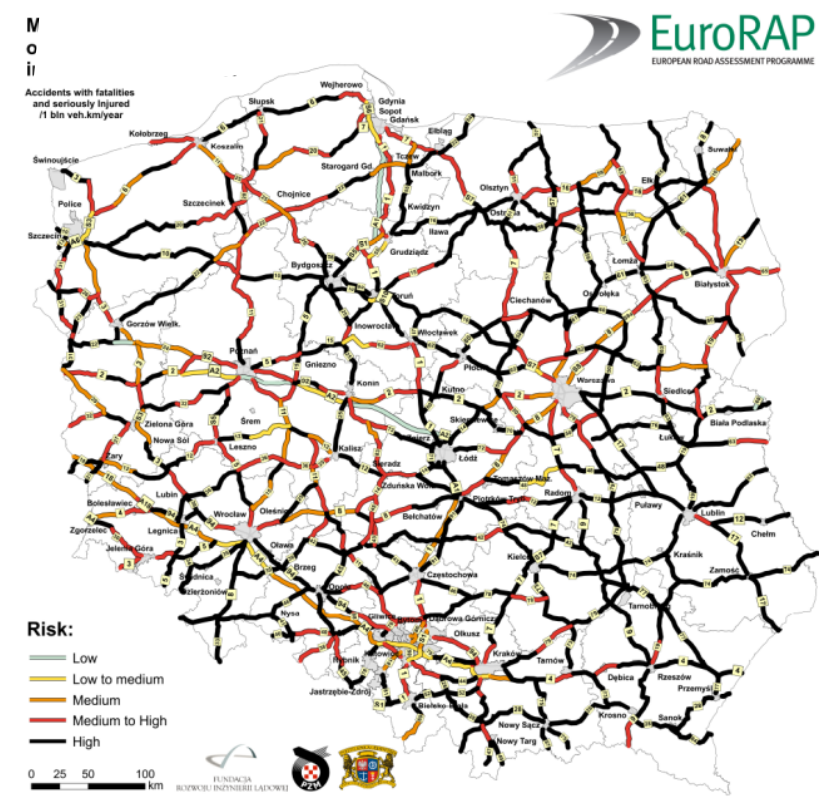

Fig. 2a. Maps of individual risk on the network of national roads: $2005-2007$ years [18]. 


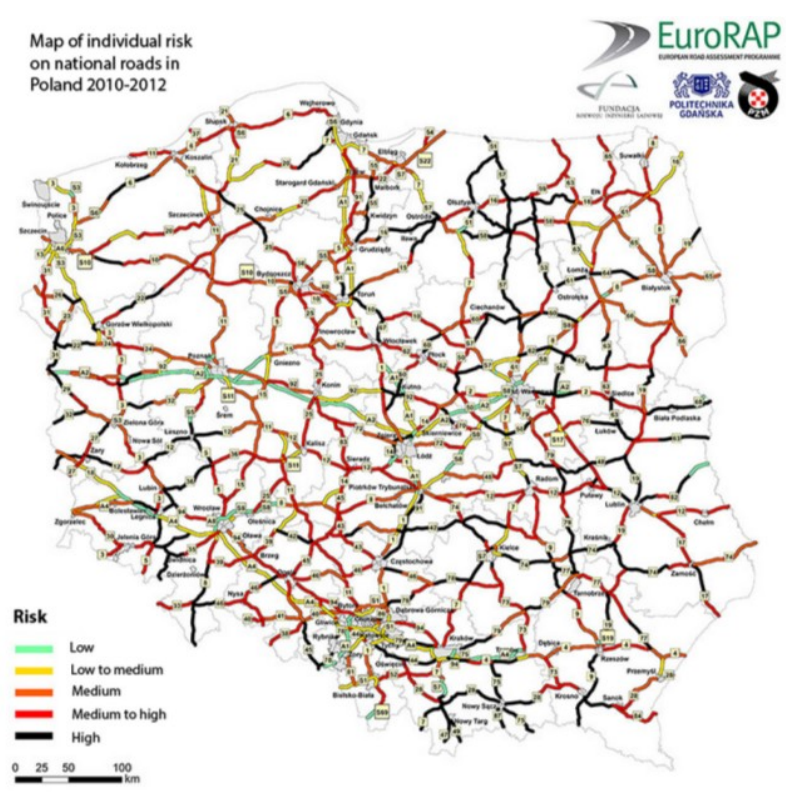

Fig. 2b. Maps of individual risk on the network of national roads: $2010-2012$ years [18].

Because fatalities on regional roads are much lower compared to national roads, the fatality criterion of road safety is simply not enough. Societal and individual risk is assessed by studying road deaths and serious injuries. This approach is in line with the EU's strategy [13] and Poland's 2013 National Road Safety Programme for the Years 2013-2020 [14]. Fig. 3 shows individual risk in terms of accident cost concentration (accident costs versus kilometres travelled) on regional roads and Fig. 4 shows societal risk (fatalities and serious injuries) by poviats. The data cover the period between 2012 and 2014 [15].

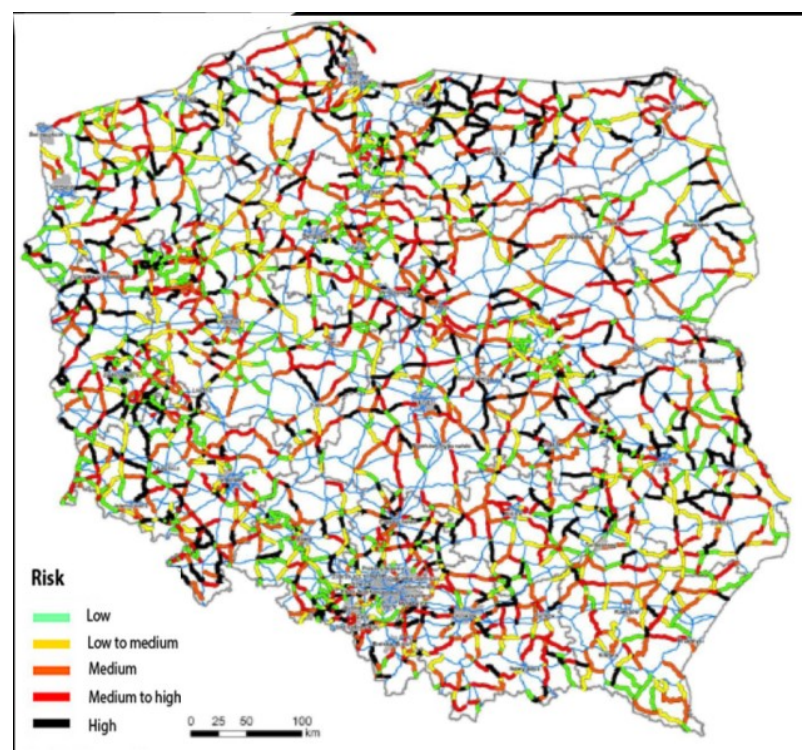

Fig. 3. Map of individual risk on regional roads [15].

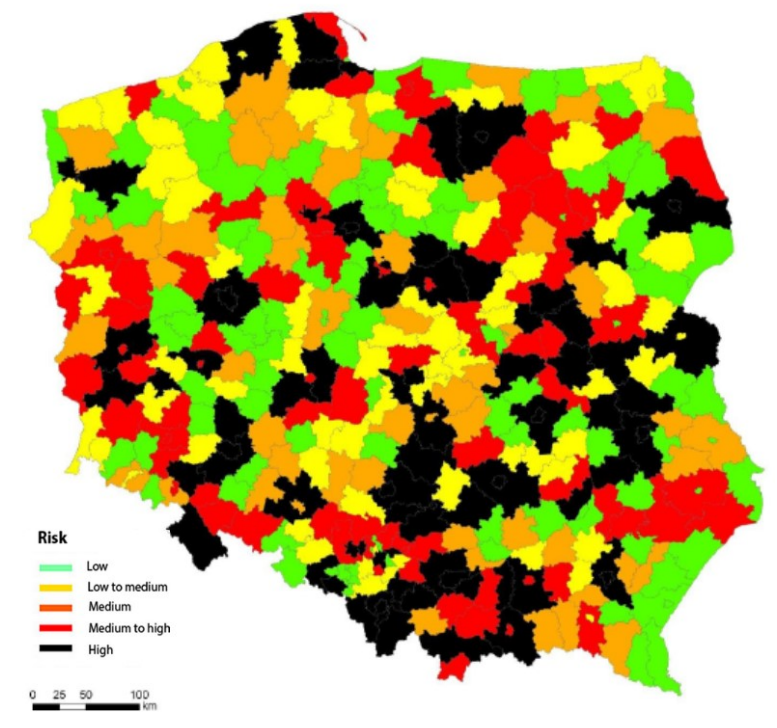

Fig. 4. Map of societal risk by poviats [15].

\section{Road data for modelling hazards}

One of the key requirements for an effective and efficient management of road infrastructure, both existing and planned, is availability of data on the level of risk and road safety on road networks, sections or junctions. The relevant decisions must be supported with a good understanding of the current road safety and the hazard that may impact safety over the coming years. [16], [17].

With access to data on accidents and traffic, we can calculate the risk measures which will help us to identify safety levels on selected elements of the road. Sections can then be identified where accident risk, fatalities and injuries are the highest [18]-[20].

Key to safety management is verifying the available data. As an example, by carefully verifying SEWIK data for the region of Warmińsko-Mazurskie in 2013 [21], it was possible to improve the accuracy of road category data by $30 \%$ (Fig. 5). This was achieved by using road records, GPS coordinates and other information.

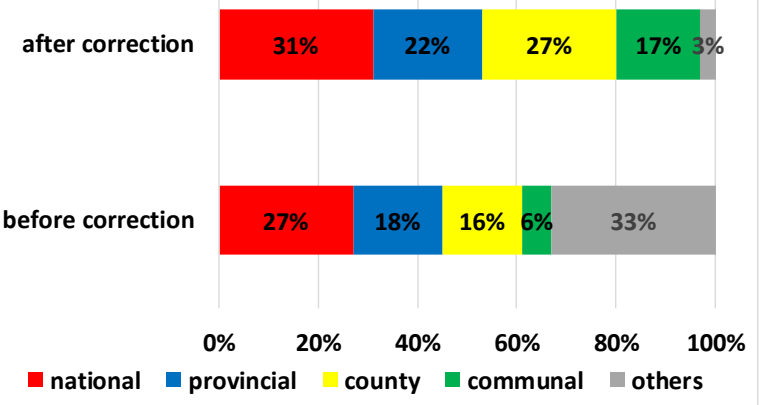

Fig. 5. Effects of road accident data verification in Warmińsko - Mazurskie [21]. 
Effective road safety management is also ensured by using data on elements of the roads. The set of independent variables that have an effect on the number and variability of section-related road safety measures is quite broad. Road safety models are built using variables of road horizontal alignment in connection with horizontal curves.

\section{Parameters of horizontal curves}

Up until now Poland's models of road safety measures have not included the parameters of horizontal curves because the relevant data are difficult to obtain. While a large part of the models contain variables that include road geometry parameters, it is not clear how they impact road safety [22]. This was addressed in previous research [22], but the samples were not big enough. Road curvature is included in models that represent long sections $(10-50 \mathrm{~km})$ [23]. Parameters of horizontal curves are particularly important in Poland due to a high number of fatalities involved in run-off-road accidents. It is estimated that app. $40 \%$ of deaths involved in run-offroad crashes occur within the area of horizontal curves. It is clear from the statistics how serious the problem is a combination of horizontal curves with dangerous roadsides. With app. $20 \%$ of all fatalities being the result of run-off-road accidents, mitigating this hazard becomes a priority. Horizontal curves and their parameters have a strong impact on road safety [24][25][26][27][19][28][29]. Horizontal curves are strictly related to speed and visibility [30]. Speed profile, profile and curvature of vehicle trajectory on horizontal curves are affected by road qualitative features such as radius, angle of turn, width of road and road surface condition as a result of the weather (dry and wet road surface) [31]. Limited sight distance involves hazards such as junctions within horizontal curves, elements of road interchanges (ramps), pedestrian crossings, etc. There may be additional hazards as a result of the demand for overtaking when speed dispersion is high. If sight distance is limited, this may lead to head-on collisions.

All these hazards and statistics show that on average in a year app. $10 \%$ of all accidents and $14 \%$ of all fatalities on Polish roads occur on horizontal curves (app. 400 fatalities). Because it is such a serious problem, road safety models must be enhanced to include horizontal curves.

\section{Methods for data acquisition}

Research conducted by the authors shows that there are other factors that affect safety on specific road sections which have not been studied in-depth so far. These factors include the number of horizontal curvatures as a sequence of connected curves, horizontal geometric parameters of curves, direction of movement on the curve and the total length of the curvature of curves.

To determine how these problems affect road safety, road sections have been selected for in-the-field research (national road no. 20, pomorskie region, lenght $20 \mathrm{~km}$ ).
One strand of the authors' work is building and testing a system for an effective horizontal curve data acquisition. The other equally important strand is analysing the data for use in the process of road safety model design. This should help select the right treatments.

Road sections were selected for data registration using the designed system. The results were then verified on those sections [32]. Fig. 6 shows a test section.

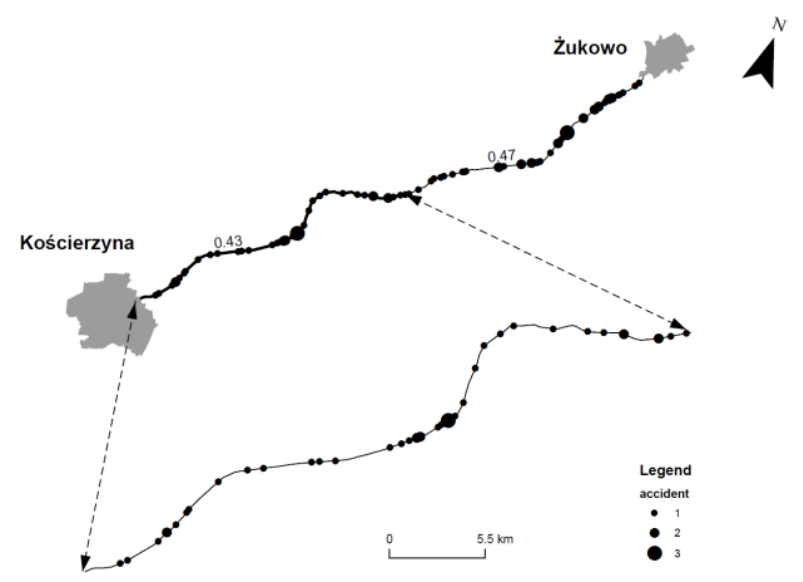

Fig. 6. A road section which was part of the inventoried measurements [32].

The experimental apparatus consists of two types of sensors. The first group is made up of three integrated digital cameras. The second includes a mobile RTK receiver (Leica Viva CS15) with a built-in GSM to ensure access to corrections made available by RTK reference stations. During the experiments adjustments were sourced from the ASG - EUPOS network. The positions registered by the receiver were transmitted in real time to a portable computer with ArcGIS software. Once collected, the data were checked for technical correctness. The checks looked at horizontal coordinates and registration errors. The idea was to determine whether the registered points put on the road's current orthophotomap are within its boundaries or not.

The data were then used to determine curve sections and analyse the parameters of the curves. The basic parameter of each curve was its length and whether it linked into a subsequent curve. The number of accidents on a particular road section provided a good background for its characteristics.

Road curvature analysis helped to develop an algorithm for determining road sections considered curves and their parameters, i.e. curve radius and curve length. The point of departure was the assumption that curvature length is an important road safety factor.

\section{Conclusion}

GIS tools support the acquisition of road parameter data. So far Poland's road safety models have not covered selected elements of road network such as horizontal curves. By using GIS we can present risk ranking in a clear and effective manner and better communicate the 
risks. This makes the tools a vital element of road infrastructure safety management. The next stage of the research and GIS tools application will be to use them in road safety inspection procedures, which is one of the road infrastructure management procedures that Poland implemented three years ago. This needs further development and improved effectiveness and efficiency.

Finally, the research should end in building a comprehensive model of the effects of road parameters on road safety measures using GIS techniques.

\section{References}

1. M. Kuźma A. Stachowicz, Rocz. Geomatyki 14 (3), 387 (2016)

2. M. Peggion, A. Bernardin, M. Masera, Geographic Information and Risk Assesment (Luxembourg: Office for Official Publications of the European Communities, 2008)

3. K. Lupton, D. Bolsdon, Comput. Environ. Urban Syst. 23 (5), 383 (1999)

4. I. Heywood, S. Cornelius, S. Carver, An Introduction To Geographical Information Systems (3rd Edition) (Pearson, 2006)

5. K. Austin, M. Tight, H. Kirby, Transp. Plan. Technol. 20 (3), 249 (1997)

6. M. Quddus, J. Transp. Saf. Secur. 5(1), 27 (2013)

7. T. Steenberghen, T. Dufays, I. Thomas, B. Flahaut, Int. J. Geogr. Inf. Sci.18 (2), 169 (2004)

8. P. C. Lai and W. Y. Chan, Ann. GIS 10 (1), 58 (2004)

9. A. S. Hakkert, L. Braimaister, and I. van Schagen, Proc. Eur. Transp. Conf. 2002 (Association for European Transport AET, London, 2002)

10. The European Parliament and the Council of Europe, DIRECTIVE 2008/96/EC on road infrastructure safety management (2008)

11. K. Jamroz, M. Budzyński, W. Kustra, L. Michalski, S. Gaca, Transp. Res. Procedia 3, 730 (2014)

12. K. Jamroz, S. Gaca, J. Gasparski, Road Traffic Safety Program for National Roads until 2013 (Association of Communications Engineers and Technicians of Poland, 2009)

13. European Commission, Road safety program 2011 2020 (2010)

14. KRBRD, National Road Safety Program 2013-2020 (2013)

15. K. Jamroz, W. Kustra, J. Wachnicka, and M. Berkowski, Risk classification methodology for selected types of road accidents on voivodeship roads as well as for voivodeships and poviats, including the classification and presentation of results on maps (Ministry of Infrastructure and Development Secretariat of the National Road Safety Council, 2015) (in Polish)

16. K. Jamroz, Risk management method in road engineering (Wydawnictwo Politechniki Gdanskiej, 2011)

17. K. Jamroz, L. Smolarek, Int. J. Occup. Saf. Ergon. 19 (2), 297 (2013)

18. M. Budzyński, K. Jamroz, W. Kustra, S. Gaca, L. Michalski, Classification of dangerous road sections on national roads GDDKiA (Gdansk University of Technology, Cracow University of Technology, 2013)

19. D. W. Harwood, F. M. Council, E. Hauer, W. E. Hughes, A. Vogt, Prediction of the Expected Safety Performance of Rural Two-Lane Highways (2000)

20. EuroRAP, Road protection score (RPS) method and pilot results, (2002)

21. J. Żukowska, T. Radzikowski, Transp. Miej. i Reg. (4), 31 (2004)

22. W. Kustra, 56 The Scientific Conference of the Committee of Civil Engineering and Water of the Polish Academy of Sciences and the Science Committee of the Polish Academy of Sciences, 329 (2010) (in Polish)

23. M. Budzyński, Characteristics of rural roads and the threat to health and life of their users, $\mathrm{PhD}$ thesis (2005)

24. F. Bella, IATSS Res. 39 (1), 51 (2015)

25. S. Mondal, Y. Lucet, W. Hare, Comput. Oper. Res. 64, 130 (2015)

26. P. Greibe, Accid. Anal. Prev. 35 (2), 273 (2003)

27. G. Khan, A. Bill, M. Chitturi, D. Noyce, Transp. Res. Rec. J. Transp. Res. Board 2279, 124 (2012)

28. F. Bella, Transp. Res. Procedia 3, 100 (2014)

29. C. Wang, M. A. Quddus, S. G. Ison, Saf. Sci. 57, 264 (2013)

30. J. Kempa, Characteristics of free movement on curvilinear stretches of roads in the plan (Wydawnictwo Uczelniane Uniwersytetu Technologiczno-Przyrodniczego, Bydgoszcz, 2008) (in Polish)

31. P. Buddhavarapu, A. Banerjee, J. A. Prozzi, Accid. Anal. Prev. 52, 9 (2013)

32. M. Budzynski, K. Jamroz, J. Pyrchla, W. Kustra, K. Pyrchla, 2016 Baltic Geodetic Congress (BGC Geomatics), 154 (2016) 